\title{
Optimization of Betalain Pigments Extraction Using Beetroot By-Products as a Valuable Source
}

\author{
Silvia Lazăr (Mistrianu) ${ }^{1}$, Oana Emilia Constantin ${ }^{1}$, Nicoleta Stănciuc ${ }^{1}$, Iuliana Aprodu ${ }^{1} @$, Constantin Croitoru ${ }^{2}$ \\ and Gabriela Râpeanu ${ }^{1, *}$ \\ 1 Faculty of Food Science and Engineering, Dunarea de Jos University of Galati, 111 Domnească Street, \\ 800201 Galati, Romania; silvia.lazar@ugal.ro (S.L.); econstantin@ugal.ro (O.E.C.); nstanciuc@ugal.ro (N.S.); \\ iaprodu@ugal.ro (I.A.) \\ 2 Academy of Agricultural and Forestry Sciences, 61 Marasti Blvd, 011464 Bucharest, Romania; \\ c.croitoru@sodinal.com \\ * Correspondence: gabriela.rapeanu@ugal.ro; Tel.: +40-336-130-177
}

check for updates

Citation: Lazăr, S.; Constantin, O.E.; Stănciuc, N.; Aprodu, I.; Croitoru, C.; Râpeanu, G. Optimization of Betalain Pigments Extraction Using Beetroot By-Products as a Valuable Source. Inventions 2021, 6, 50. https:// doi.org/10.3390/inventions6030050

Academic Editor: Monique Lacroix

Received: 24 June 2021

Accepted: 10 July 2021

Published: 14 July 2021

Publisher's Note: MDPI stays neutral with regard to jurisdictional claims in published maps and institutional affiliations.

Copyright: (c) 2021 by the authors. Licensee MDPI, Basel, Switzerland. This article is an open access article distributed under the terms and conditions of the Creative Commons Attribution (CC BY) license (https:// creativecommons.org/licenses/by/ $4.0 /)$.

\begin{abstract}
Background: This study is designed to extract the bioactive compounds from beetroot peel for future use in the food industry. (2) Methods: Spectrophotometry techniques analyzed the effect of conventional solvent extraction on betalains and polyphenolic compounds from beetroot peels. Several treatments by varying for factors (ethanol and citric acid concentration, temperature, and time) were applied to the beetroot peel samples. A Central Composite Design (CCD) has been used to investigate the effect of the extraction parameters on the extraction steps and optimize the betalains and total polyphenols extraction from beetroot. A quadratic model was suggested for all the parameters analyzed and used. (3) Results: The maximum and minimum variables investigated in the experimental plan in the coded form are citric acid concentration (0.10-1.5\%), ethanol concentration $(10-50 \%)$, operating temperature $\left(20-60{ }^{\circ} \mathrm{C}\right)$, and extraction time (15-50 $\left.\mathrm{min}\right)$. The experimental design revealed variation in betalain content ranging from 0.29 to $1.44 \mathrm{mg} / \mathrm{g}$ DW, and the yield of polyphenolic varied from 1.64 to $2.74 \mathrm{mg} / \mathrm{g}$ DW. The optimized conditions for the maximum recovery of betalains and phenols were citric acid concentration $1.5 \%$, ethanol concentration $50 \%$, temperature $52.52{ }^{\circ} \mathrm{C}$, and extraction time $49.9 \mathrm{~min}$. (4) Conclusions: Overall, it can be noted that the extraction process can be improved by adjusting operating variables in order to maximize the model responses.
\end{abstract}

Keywords: beetroot peel; betalains; polyphenols; CCD-RSM

\section{Introduction}

Beetroot (Beta vulgaris L.) is a plant belonging to Chenopodiaceae's family that includes approximately 105 genera with 1400 species [1], which is widely grown in Europe, America, and Asia [2]. Similarly, red beetroot is perhaps the most generally planted root vegetable in Southeast Romania. The edible portion of the beets used in the food sector is the tuberous root. The leaves are also used but are generally considered feedstuff material. Beets are available mainly in the cold season but are also adapted to high temperatures. The optimum growth temperature varies between 15 and $19{ }^{\circ} \mathrm{C}$, with lower temperatures influencing the red pigment increase. The beetroot was cultivated especially for medicinal purposes but was used predominantly for food and drink from the beginning of the third century [3]. The best-known existing species are sugar beet (Beta vulgaris saccharifera), fodder beet (Beta vulgaris crassa), leaf beet (Beta vulgaris cicla), and garden beet (Beta vulgaris rubra).

In general, beetroot is a vegetable rich in carotenoids, flavonoids, vitamins (niacin, biotin, pyridoxine), and minerals (such as potassium, sodium, phosphorus, calcium, magnesium, copper, iron, zinc, etc.) [4]. Beetroot is also one of the richest sources of betalains, which are plant pigments derived from the betalamic acid that are soluble in water and responsible for an intense red (betacyanins) or yellow color (betaxanthins) [5]. The intensity 
of beet color depends on the ratio between betacyanins and betaxanthins. More than $80 \%$ of all beet pigments are betacyanin compounds [6]. Betalains from Beta vulgaris rubra are natural food coloring, being antiradical and antioxidant agents capable of protecting in vivo from disorders caused by oxidative stress. The functions of betalains refer to reduction of homocysteine concentration, which regulates vascular homeostasis, maintaining platelet function, thrombotic activity, vascular tone, and delicate stability by the release of vasodilators and vasoconstrictors. Some effects attributed to these compounds include antioxidants [7,8], antiproliferative [9], cardioprotective [10], anti-inflammatory [11], and antimicrobial effects [12].

Betalains found in red beetroot are utilized to color various food items, for example, frozen yogurt, wine, jams, and yogurt [13]. Extraction is an essential step in the process of separating biologically active compounds. There are many extraction methods, but the most used method is conventional solvent extraction. It is widely used due to its efficiency, short extraction time, and low economic costs despite the disadvantages, such as using large amounts of solvent [14].

Betalains are usually extracted from plant matrices by conventional solvent extraction (CSE) methods and Soxhlet extraction $[15,16]$. In this study, conventional solvent extraction was used by varying four factors (ethanol concentration, citric acid, temperature, time, agitation rpm). Furthermore, for more efficient solid/liquid extraction under stirring of biologically active compounds from beetroot peel, a central composite design (CCD) was used in order to optimize the extraction procedure to maximize both phenolic compounds extraction and betalains.

\section{Materials and Methods}

\subsection{Reagents and Chemicals}

For the phytochemical characterization of biologically active compounds from beetroot, peels were used: ethanol of HPLC purity, ethanol, citric acid, Folin-Ciocâlteu reagent, and gallic acid solution were obtained from Sigma Aldrich (St. Louis, MO, USA).

\subsection{Beetroot Peels Powder}

A local producer in Galati County provided beetroot. After being thoroughly washed, the shells were removed with a knife. The resulting beetroot peel was washed with ultrapure water, wiped, and frozen for drying. Drying was performed by the lyophilization technique using CHRIST Alpha 1-4 LD. Plus equipment, Germany, at $-42{ }^{\circ} \mathrm{C}$, under a pressure of $0.10 \mathrm{mBar}$, for $48 \mathrm{~h}$. The resulting dry peels had a relative humidity of $1 \%$. They were grounded and stored in a glass container with an airtight lid at room temperature and in the dark.

\subsection{Conventional Solvent Extraction}

The extraction was performed using $1 \mathrm{~g}$ of beet peel with $10 \mathrm{~mL}$ of ethanol in different concentrations, respectively $9-60 \%$. The ratio of plant material to the solvent was 1 to 10 . Each extraction was acidified with a citric acid solution using different concentrations of $0.03-2 \%$, in a ratio of 1 to 9 . The extractions took place at $3-87^{\circ} \mathrm{C}$ for 3 to $74 \mathrm{~min}$ on an orbital shaker (SI-300R Medline Scientific, Chalgrove, UK) at $100 \mathrm{rpm}$. Subsequently, the samples were centrifuged using Hettich Universal 320R equipment, Germany, for $10 \mathrm{~min}$ at $14,000 \mathrm{rpm}$, at $4{ }^{\circ} \mathrm{C}$, and the supernatant was phytochemically analyzed.

\subsection{Determination of Total Betalains (TB) Content}

The total betalains (TB) content of the beet peels extract was determined using a spectrophotometric method based on absorbance measurement at two different wavelengths, respectively $480 \mathrm{~nm}$ for betaxanthins and $537 \mathrm{~nm}$ for betacyanins. 
The total betalains (TB) content was expressed in $\mathrm{mg} / \mathrm{g}$ DW and was calculated as the sum of betacyanins and betaxanthins according to Formula (1) as described by Wruss et al. [2], with slight modifications.

$$
B C[\mathrm{mg} / \mathrm{g}]=\frac{A \cdot D F \cdot M_{w} \cdot V_{d}}{\varepsilon \cdot L \cdot W_{d}}
$$

where $A$ is the maximum absorption value of $537 \mathrm{~nm}$ for betacyanins and $480 \mathrm{~nm}$ for betaxanthins; $D F$ is the dilution factor; $V_{d}$ is the volume of dry pulp solution $(\mathrm{mL}) ; W_{d}$ is the weight of the dried pulp $(\mathrm{g}) ; L$ is the length of the tank path $(1 \mathrm{~cm}) ; M_{W}$ is the molecular weight of betalains $(550 \mathrm{~g} / \mathrm{mol}) ; \varepsilon$ is the the extinction coefficient of betalain; $\varepsilon$ of $60,000 \mathrm{~L} / \mathrm{mol} \mathrm{cm}$ in $\mathrm{H}_{2} \mathrm{O}$ were applied to quantify betacyanins, and the quantitative equivalents of major betaxanthins $(\mathrm{Bx})$ were determined by applying the average molar extinction coefficient $(\varepsilon) 48,000 \mathrm{~L} /(\mathrm{mol} \cdot \mathrm{cm})$ in $\mathrm{H}_{2} \mathrm{O}$.

\subsection{Determination of Total Polyphenol Content (TPC)}

The total polyphenol content (TPC) of the beet peels extract was determined using the Folin-Ciocalteu (FC) method. The description of this method is based on the redox reaction between phenolic compounds and a mixture of tungsten and molybdenum in an alkaline environment. This reaction leads to the creation of a blue complex that was quantified at $765 \mathrm{~nm}$. The results were expressed as $\mathrm{mg}$ gallic acid equivalent (GAE)/g DW.

\subsection{Statistical Analysis}

To analyze the experimental model, we used statistical software Design Expert (v. 13) from Design-Expert ${ }^{\circledR}$ (Stat-Ease, Inc., minneapolis, MN, USA).

\subsection{Experimental Design}

Central Composite Design (CCD) has been used to optimize the extraction of betalains and total polyphenols from beetroot and establish the experimental antioxidant activity. An experimental factorial model with a central composition with five factors, three central points, and the design of 19 experimental variants was used. The maximum and minimum ranges of the variables investigated in the experimental plan in the current form and the coded form are presented in Table 1. In addition, CCD builds a quadratic model for response variables.

Table 1. Range factors studied and the corresponding encoded values.

\begin{tabular}{ccccccc}
\hline Code & Independent Variables & Units & Minimum & Maximum & Coded Low & Coded High \\
\hline A & Citric acid & $\%$ & 0.03 & 1.98 & $-1 \leftrightarrow 0.10$ & $+1 \leftrightarrow 1.50$ \\
B & Ethanol & $\%$ & 9.77 & 60.23 & $-1 \leftrightarrow 20.00$ & $+1 \leftrightarrow 50.00$ \\
C & Temperature & ${ }^{\circ} \mathrm{C}$ & 2.96 & 87.04 & $-1 \leftrightarrow 20.00$ & $+1 \leftrightarrow 60.00$ \\
D & Time & $\min$ & 3.07 & 61.93 & $-1 \leftrightarrow 15.00$ & $+1 \leftrightarrow 50.00$ \\
\hline
\end{tabular}

The software used for testing the experimental conditions can be described by a second-order polynomial model (2):

$$
R=b_{0}+\sum_{i=1}^{n} b_{i} \cdot x_{i}+\sum_{i=1}^{n} b_{i i} \cdot x_{i}^{2}+\sum_{i \neq j=1}^{n} b_{i j} \cdot x_{i} \cdot x_{j}
$$

where $R$-predicted response, $b_{0}$-intercept, $b_{i}, b_{i i}$, and $b_{i j}$-regression coefficients, $x_{i}$ and $x_{j}$-independent variables analyzed, $n$-number of factors.

\section{Results}

In order to determine the optimal parameters for optimization of the extraction process, a Central Composite Design (CCD) and surface response modeling were used. In addition, 
the BT and TPC contents were measured in response. Table 2 shows the complete CCD matrix used to optimize the main variables studied and the corresponding values.

Table 2. The CCD matrix with the actual values of the main variables studied.

\begin{tabular}{|c|c|c|c|c|c|c|}
\hline Run & $\begin{array}{c}\text { Factor } 1 \\
\text { A: Citric Acid } \\
\%\end{array}$ & $\begin{array}{c}\text { Factor } 2 \\
\text { B: Ethanol } \\
\quad \%\end{array}$ & $\begin{array}{c}\text { Factor } 3 \\
\text { C: Temperature } \\
{ }^{\circ} \mathrm{C}\end{array}$ & $\begin{array}{l}\text { Factor } 4 \\
\text { D: Time } \\
\text { min }\end{array}$ & $\begin{array}{c}\text { Response } 1 \\
\text { Betalains } \\
\text { mg/g DW }\end{array}$ & $\begin{array}{c}\text { Response } 2 \\
\text { TPC } \\
\text { mg GAE/g DW }\end{array}$ \\
\hline 1 & 0.80 & 35.00 & 40.00 & 3.07 & 0.80 & 2.02 \\
\hline 2 & 0.80 & 35.00 & 40.00 & 32.50 & 0.98 & 2.30 \\
\hline 3 & 1.98 & 35.00 & 40.00 & 32.50 & 1.03 & 2.38 \\
\hline 4 & 0.10 & 50.00 & 20.00 & 50.00 & 0.88 & 2.12 \\
\hline 5 & 0.10 & 50.00 & 60.00 & 50.00 & 0.70 & 1.92 \\
\hline 6 & 1.50 & 20.00 & 20.00 & 50.00 & 0.85 & 2.00 \\
\hline 7 & 1.50 & 20.00 & 60.00 & 50.00 & 0.62 & 1.80 \\
\hline 8 & 0.80 & 35.00 & 6.36 & 32.50 & 0.65 & 1.89 \\
\hline 9 & 0.80 & 35.00 & 40.00 & 32.50 & 1.02 & 2.28 \\
\hline 10 & 1.50 & 50.00 & 60.00 & 15.00 & 0.76 & 1.96 \\
\hline 11 & 0.10 & 20.00 & 20.00 & 15.00 & 0.78 & 2.05 \\
\hline 12 & 0.80 & 35.00 & 73.64 & 32.50 & 0.29 & 1.64 \\
\hline 13 & 0.03 & 35.00 & 40.00 & 32.50 & 0.67 & 1.99 \\
\hline 14 & 0.80 & 60.23 & 40.00 & 32.50 & 1.44 & 2.74 \\
\hline 15 & 0.80 & 35.00 & 40.00 & 61.93 & 1.14 & 1.87 \\
\hline 16 & 1.50 & 50.00 & 20.00 & 15.00 & 0.99 & 2.22 \\
\hline 17 & 0.80 & 35.00 & 40.00 & 32.50 & 1.10 & 2.26 \\
\hline 18 & 0.80 & 9.77 & 40.00 & 32.50 & 0.65 & 1.81 \\
\hline 19 & 0.10 & 20.00 & 60.00 & 15.00 & 0.36 & 1.77 \\
\hline
\end{tabular}

\subsection{The Influence of Extraction Parameters on BT}

This study aimed to identify the proper optimal pattern of factors for the betalains extraction from beetroot. The experimental design revealed a variation in betalain content ranging from 0.29 to $1.44 \mathrm{mg} / \mathrm{g}$ DW (Table 2).

The regression equations obtained after the analysis of the ANOVA variance described the content in BT of the beet extract obtained, depending on the factors of the extraction environment (Table 3).

The regression model acquired for BT revealed a determination coefficient of $\mathrm{R}^{2}=$ 0.96 , suggesting that only 0.04 of the variation of BT cannot be described by the current model. The Lack of Fit F-value of 1.12 implies that the Lack of Fit is not significant relative to the pure error. $p$-values less than 0.0500 indicate that model terms are significant, and in this case, $\mathrm{A}, \mathrm{B}, \mathrm{C}, \mathrm{D}, \mathrm{AB}, \mathrm{AD}, \mathrm{A}^{2}$, and $\mathrm{C}^{2}$ are significant model terms.

The minor model terms were excluded, and a model reduction was achieved. As a result, the model equation indicating the relationship between the betalains content (R1) and variables in coded units is represented in Equation (3). Moreover, the Pred $R^{2}(0.8796)$ values were in reasonable agreement with $\mathrm{Adj}^{2} \mathrm{R}^{2}(0.9452)$.

$R 1(B T)=+1.01+0.08 \mathrm{~A}+0.23 \mathrm{~B}-0.12 \mathrm{C}+0.1011 \mathrm{D}+0.08 \mathrm{AB}+0.14 \mathrm{AD}-0.06 \mathrm{~A}^{2}-0.19 \mathrm{C}^{2}$

The $b$ coefficients from the regression equation indicated that the temperature had a significant negative effect on betalain extractions. In addition, the interactions between temperature and temperature $\left(\mathrm{C}^{2}\right)$ have significant negative effects, and quadratic citric acid concentration $\left(\mathrm{A}^{2}\right)$ had a more negligible contribution. Furthermore, ethanol concentration (B) and extraction time (D) appreciably positively influenced the BT. The interaction between temperature and extraction time $(\mathrm{AB})$ moderately affected the extraction, while citric acid concentration and ethanol concentration (AD) have a better effect. 
Table 3. ANOVA for the reduced quadratic model for BT and TPA extractions.

\begin{tabular}{|c|c|c|c|c|c|c|c|c|c|c|}
\hline \multicolumn{6}{|c|}{ Total Betalains (TB) Content } & \multicolumn{5}{|c|}{ Total Polyphenol Content (TPC) } \\
\hline Source & $\begin{array}{l}\text { Sum of } \\
\text { Squares }\end{array}$ & df & $\begin{array}{l}\text { Mean } \\
\text { Square }\end{array}$ & F-Value & $p$-Value & $\begin{array}{l}\text { Sum of } \\
\text { Squares }\end{array}$ & df & $\begin{array}{l}\text { Mean } \\
\text { Square }\end{array}$ & F-Value & $p$-Value \\
\hline Model & 1.30 & 8 & 0.1625 & 39.84 & $<0.0001^{\mathrm{a}}$ & 1.22 & 9 & 0.1356 & 80.87 & $<0.0001$ \\
\hline A-Citric acid & 0.0898 & 1 & 0.0898 & 22.02 & 0.0009 & 0.0765 & 1 & 0.0765 & 45.61 & $<0.0001$ \\
\hline B-Ethanol & 0.3120 & 1 & 0.3120 & 76.50 & $<0.0001$ & 0.4336 & 1 & 0.4336 & 258.56 & $<0.0001$ \\
\hline C-Temperature & 0.2026 & 1 & 0.2026 & 49.67 & $<0.0001$ & 0.1340 & 1 & 0.1340 & 79.93 & $<0.0001$ \\
\hline D-Time & 0.0578 & 1 & 0.0578 & 14.17 & 0.0037 & 0.0125 & 1 & 0.0125 & 7.44 & 0.0233 \\
\hline $\mathrm{AB}$ & 0.0213 & 1 & 0.0213 & 5.23 & 0.0453 & 0.1383 & 1 & 0.1383 & 82.49 & $<0.0001$ \\
\hline $\mathrm{AD}$ & 0.0687 & 1 & 0.0687 & 16.85 & 0.0021 & 0.0345 & 1 & 0.0345 & 20.58 & 0.0014 \\
\hline $\mathrm{A}^{2}$ & 0.0567 & 1 & 0.0567 & 13.90 & 0.0039 & 0.0097 & 1 & 0.0097 & 5.77 & 0.0397 \\
\hline$C^{2}$ & 0.5475 & 1 & 0.5475 & 134.20 & $<0.0001$ & 0.4186 & 1 & 0.4186 & 249.63 & $<0.0001$ \\
\hline $\mathrm{D}^{2}$ & - & - & - & - & - & 0.1666 & 1 & 0.1666 & 99.38 & $<0.0001$ \\
\hline Residual & 0.0408 & 10 & 0.0041 & & & 0.0151 & 9 & 0.0017 & & \\
\hline Lack of Fit & 0.0333 & 8 & 0.0042 & 1.12 & $0.5545^{b}$ & 0.0145 & 7 & 0.0021 & 7.58 & 0.1215 \\
\hline Pure Error & 0.0075 & 2 & 0.0037 & & & 0.0005 & 2 & 0.0003 & & \\
\hline Cor Total & 1.34 & 18 & & & & 1.24 & 18 & & & \\
\hline
\end{tabular}

SS-Sum of Squares, MS-Mean Square; ${ }^{\text {a }}$ Significant; ${ }^{\mathrm{b}}$ Not significant.

Figure 1a represents the correlation between ethanol and citric acid concentration on the extraction yield. The betalain content increased as the ethanol concentration increase to $40 \%$ and from $1.30 \%$ for the citric acid concentration. Betalains extraction was influenced by the citric acid concentration and extraction time correlative effect (Figure 1b). Extraction was inhibited both at low concentrations of citric acid $(0.10 \%)$ and at high concentrations exceeding $1.50 \%$. Similarly, the extraction time negatively affects the process at values greater than $50 \mathrm{~min}$ and less than $15 \mathrm{~min}$. It can be concluded that by increasing the extraction time and decreasing the concentration of citric acid in the extraction medium, the extraction yield decreases significantly.
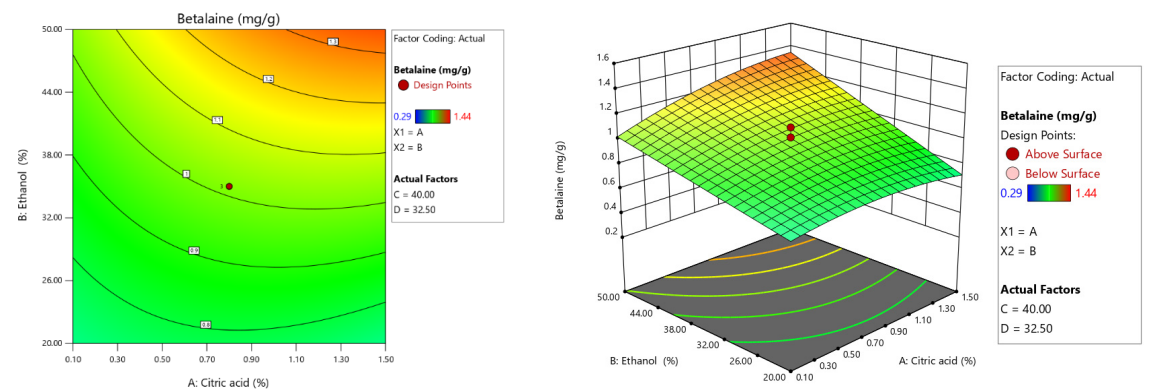

(a)
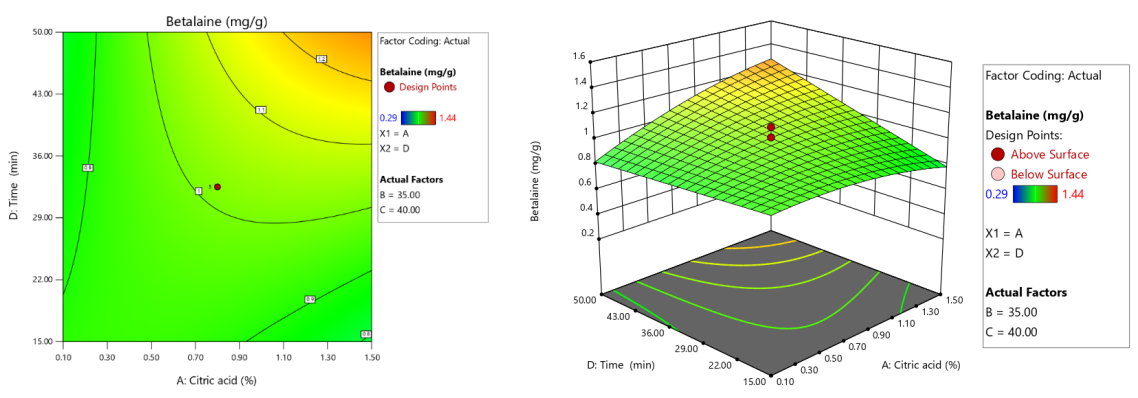

(b)

Figure 1. Second-order contour plots (left) and 3D surface plots (right) screening the effect of ethanol and citric acid concentra-tion (a) and extraction time and citric acid concentration (b) on the extraction yield of total betalain content (BT).

In analyzing the deviation from the reference point, a slope with a large or curved inclination for a specific factor shows that the response is sensitive in this case, while a relatively 
flat line demonstrates insensitivity to changes in this factor. The main factor affecting BT extraction is the ethanol (Figure 2a, curve B) followed by temperature (Figure 2a, curve C) and extraction time (Figure $2 a$, curve D). Meanwhile, the findings showed that citric acid is less sensitive (Figure 2a, curve A).

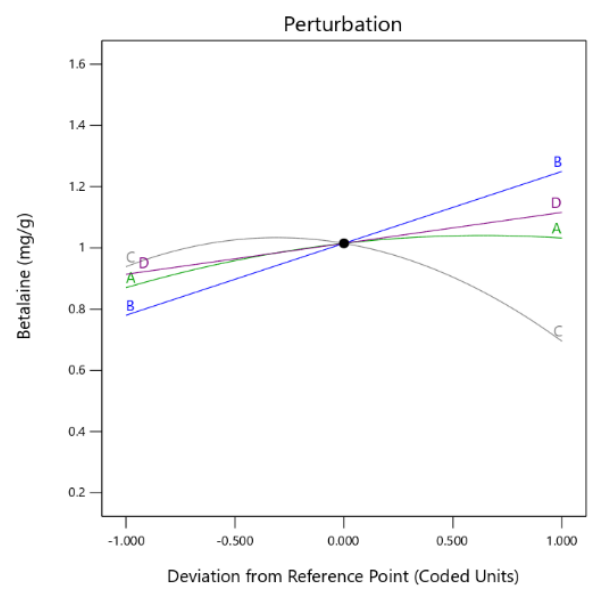

(a)

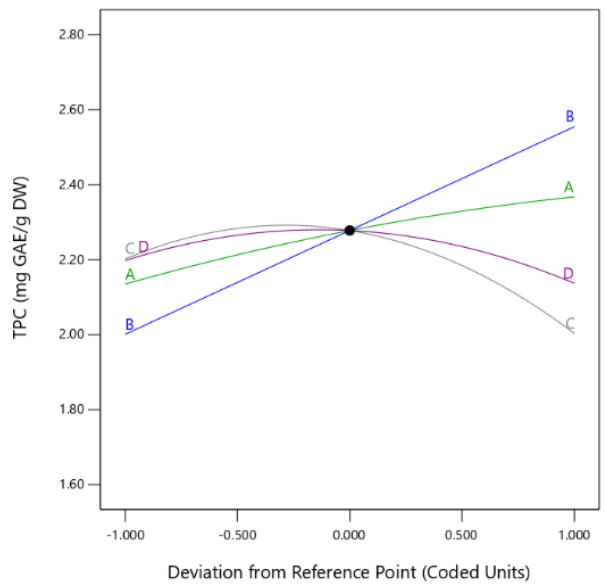

(b)

Figure 2. Graph of perturbations describing the effect of each independent variable (A, B, C, and D) on BT (a) and TPC (b) extraction.

\subsection{The Influence of Extraction Parameters on TPC}

Due to the effect of different variables, the yield of polyphenolic varied from 1.64 to $2.74 \mathrm{mg} / \mathrm{g}$ DW (Table 2).

The Model F-value of 80.87 implies that the model is significant. The determinant coefficient of $\mathrm{R}^{2}=0.98$ suggests that only 0.02 of the variation of TPC cannot be described by the current model. Subsequently, from Table 3, it was observed that the Lack of Fit F-value of 7.58 implies the Lack of Fit lack was non-significant, which showed that the model is also significant. $p$-values less than 0.0500 indicate that model terms are significant, and in this case, they are significant model terms. In this case, $A, B, C, D, A D, B D, A^{2}, C^{2}$, and $\mathrm{D}^{2}$ are significant model terms.

The insignificant model terms were ignored, and a model reduction was attained. The model equation indicating the relationship between the total phenolic content $\left(\mathrm{R}^{2}\right)$ and variables in coded units was represented in Equation (4). Moreover, the Pred $\mathrm{R}^{2}$ values (0.8875) were in reasonable agreement with $\mathrm{Adj} \mathrm{R}^{2}$ (0.9756).

$\mathrm{R}^{2}(\mathrm{TPC})=+2.28+0.11 \mathrm{~A}+0.27 \mathrm{~B}-0.99 \mathrm{C}-0.30 \mathrm{D}+0.20 \mathrm{AD}+0.10 \mathrm{BD}-0.26 \mathrm{~A}^{2}-0.17 \mathrm{C}^{2}-0.11 \mathrm{D}^{2}$

The $b$ coefficients from the regression equation indicated that the temperature and time had a minor negative effect on TPC extractions. On the other hand, the extraction time positively affects the TPC recovery when associated with ethanol and citric acid concentration. In addition, significant negative effects have the interactions between temperature and temperature $\left(C^{2}\right)$ and time and time $\left(D^{2}\right)$. Furthermore, ethanol concentration $(B)$ and citric acid concentration (A) had an appreciably positive effect on polyphenols extractions.

Second-order contour plots were designed to predict the relationship between the independent and dependent variables (Figure 3) and to illustrate the synergistic effects of the independent factors on the TPC. The three-dimensional response area describes the correlative effect of the selected factors on TPC. The coordinates of the central point in the contour graph correspond to the optimal concentration of the four components of the extraction process to obtain a maximum phenolic extraction efficiency. 

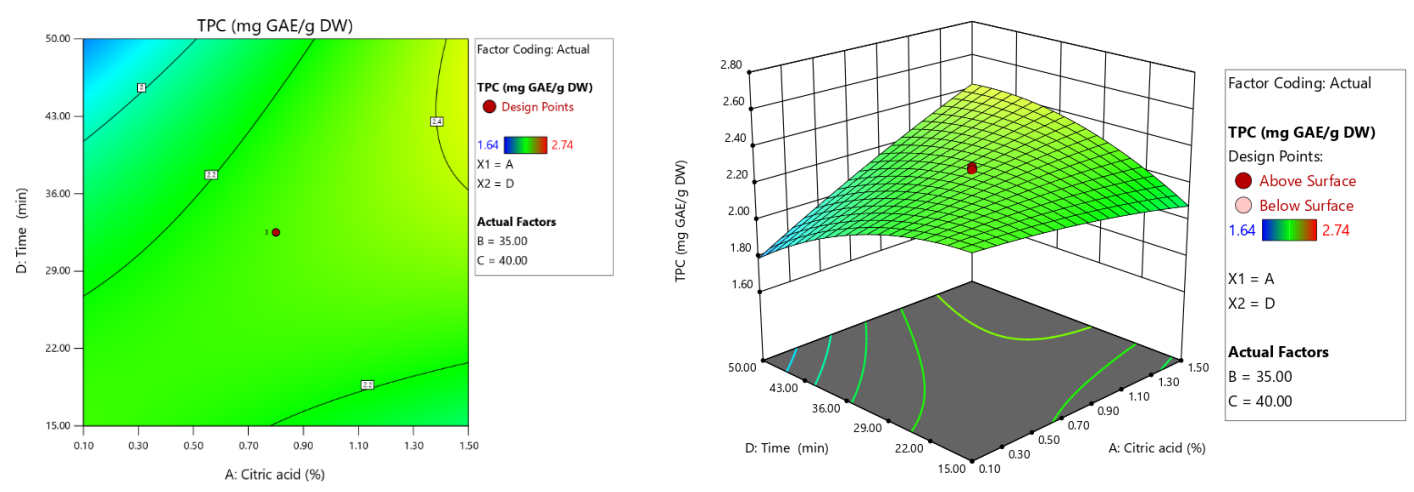

(a)
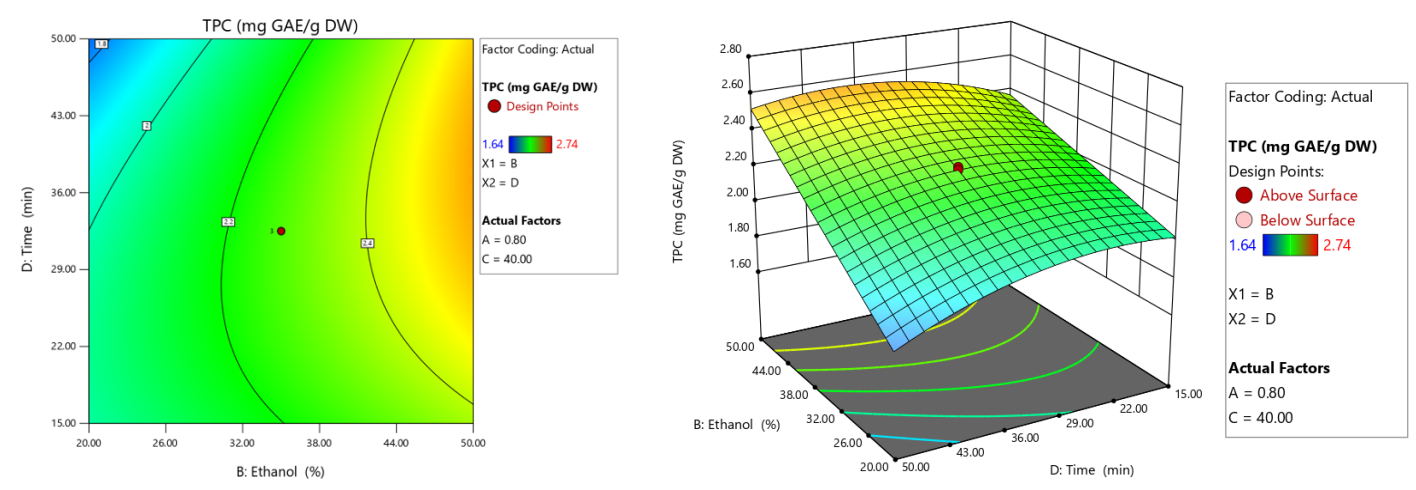

(b)

Figure 3. Second-order contour plots (left) and 3D surface plots (right) screening the effect of extraction time and citric acid concentration (a) and extraction time and ethanol (b) on the extraction yield of total phenolic content (TPC).

The effects of varying extraction time and citric acid concentration on the extraction of phenolic compounds are shown in Figure 3a. The concentration of polyphenols is lower as the extraction time and the concentration of citric acid increase simultaneously. Figure $3 \mathrm{~b}$ confirmed that the extraction was not influenced by time variation but was influenced by ethanol concentration.

According to the perturbations graph describing the effect of each independent variable, the TPC has strongly influenced ethanol concentration and, to a lesser extent, temperature and time have influenced the concentration as well (Figure 2b, curve B, C, and D). Thus, a maximum of $2.74 \mathrm{mg} \mathrm{GAE} / \mathrm{g}$ DW was found at $40{ }^{\circ} \mathrm{C}$ at the maximum ethanol concentration $(60.23 \%)$ in the present study.

\subsection{Optimization and Validation of Extraction Parameters}

The model suggested the optimal conditions based on the maximization of the responses desirability to validate the model equation. A value of desirability near 1 (0.956) suggested that all the selected conditions were in a proper combination (Figure 4, Table 4).

The optimal conditions for the maximum recovery of betalains and phenols were citric acid concentration $1.5 \%$, ethanol concentration $50 \%$, temperature $52.52{ }^{\circ} \mathrm{C}$, and extraction time of $49.9 \mathrm{~min}$.

The model estimated the maximum concentration of betalains and total polyphenols of $1.15 \mathrm{mg} / \mathrm{g}$ DW and $2.44 \mathrm{mg} \mathrm{GAE} / \mathrm{g}$ DW, respectively, and the experimental results indicated immediate responses to those predicted by the model, namely $1.20 \mathrm{mg} / \mathrm{g} \mathrm{DW}$ and $2.39 \mathrm{mg}$ GAE/g DW (Table 4). 


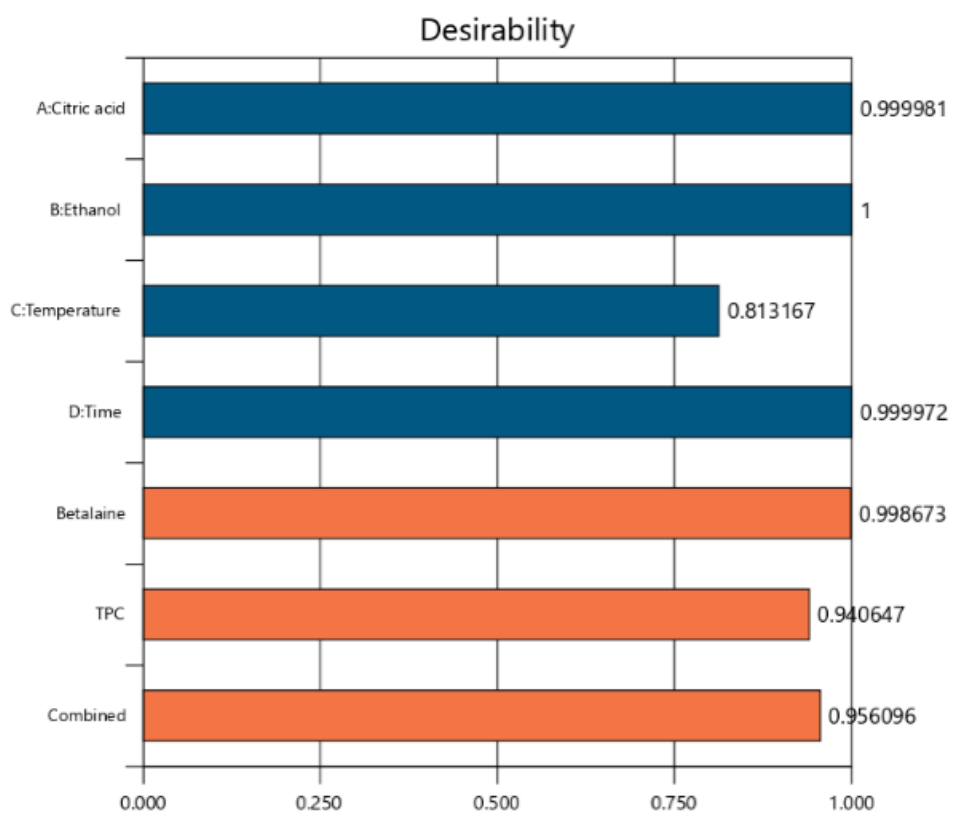

Figure 4. Desirability plot of process parameters and responses.

Table 4. Validation of the mathematical model.

\begin{tabular}{cccc}
\hline Dependent Variable & Predicted Value & $\mathbf{9 5 \%}$ Confidence Intervals & Experimental Value \\
\hline BT $(\mathrm{mg} / \mathrm{g} \mathrm{DW})$ & 1.15 & $1.06-1.25$ & 1.20 \\
TPC $(\mathrm{mg} \mathrm{GAE} / \mathrm{g}$ DW $)$ & 2.44 & $2.39-2.49$ & 2.39 \\
\hline
\end{tabular}

\section{Discussion}

The phytochemicals extraction from plant materials relies upon the extraction strategy being influenced by the extraction parameters used. Moreover, the various polarities of compounds extracted by applying the experimental model could have an unpredictable impact on the extraction conditions. Hence, extractions were performed with extractants having various polarities controlled by adjustments in the water and ethanol. Adding ethanol to water may increase the betalain extraction yields [17], and the extracts can be easily used in biological systems. Moreover, the extraction optimization led to adding citric acid in the extraction mixture to acidify the medium, mainly because the betalains became stable at $\mathrm{pH} 3-7$ [18].

The results from the CCD indicated that the temperature had a minor negative effect on TPC extractions. The results agree with [19] that revealed that the temperature does not bring any significant transformation of betalains content. The CCD matrix revealed that the low temperature of $6.3{ }^{\circ} \mathrm{C}$ is insufficient for the total extraction of betalains, and also, the higher temperatures of $73.54{ }^{\circ} \mathrm{C}$ have a negative influence on betalains that can lead to their degradation [20]. The results agree with [21], which achieved the same conclusions at temperatures of $50{ }^{\circ} \mathrm{C}$. In the same pattern the authors of [22] found that the maximum betalain retention was 25 to $30{ }^{\circ} \mathrm{C}$, and by increasing the temperature of extraction, a decreased in betalain retention was accomplished.

However, a study conducted by [23] to determine the optimization of betalain pigments extraction from xoconostle using RMS methodology found contrasting findings. The authors obtained a maximum concentration of $0.92 \mathrm{mg} / \mathrm{g}$ of fruit at a lower temperature of extraction of $15^{\circ} \mathrm{C}$ for $10 \mathrm{~min}$ using as solvent methanol and a ratio of 20:80 (methanol:water).

The results from the optimization experiment indicate that the factors affecting BT extraction are the ethanol concentration and time. Since betalains are sensitive to high temperature and long processing times, we have searched for a possible green method to keep these compounds in the product. Several authors obtained similar findings $[24,25]$. 
Similar quantities of betalains of 0.8 and $1.3 \mathrm{mg} / \mathrm{g}$ juice were obtained by analyzing different beetroot varieties from Upper Austria [2]. The authors of [26] indicated values of $0.4-20 \mathrm{mg} / \mathrm{g}$ betalains in red beetroot. In addition, in a study conducted by [27] for different beetroot species, a content of $0.65-0.80 \mathrm{mg} / \mathrm{g}$ FM betalain was obtained. Moreover, in a comparative study that analyzed the different parts and cultivars of beetroot for betalain profiling, a variation in the content of betalains was observed [28]. The betalains distribution obtained was from 5.33 to $31.04 \mathrm{mg} / \mathrm{g}$ DW for peel, from 0.35 to $8.65 \mathrm{mg} / \mathrm{g}$ DW for the flesh, and 0.85 to $11.10 \mathrm{mg} / \mathrm{g}$ DW for the petiole.

The authors of [29] reported lower values of TPC of $1.77 \mathrm{mg}$ GAE/g DW than this study. Low values were also obtained by [30] that the total polyphenols range from 0.82 to $1.28 \mathrm{mg} / \mathrm{g}$ DW for two beetroot varieties. A similar study that analyzed four beetroot varieties revealed after extraction a phenolic content of $0.365-8.87 \mathrm{mg} / \mathrm{g}$ DW using the following parameters: solvent, $80 \%$ ethanol, and $12 \mathrm{~h}$ as the extraction time [31]. Another study [32] achieved a total phenolic amount of between 3.52 and $4.89 \mathrm{mg}$ GAE/g DW for the red-colored genotypes.

\section{Conclusions}

CCD-RSM was employed to optimize the solvent extraction process variables to produce beetroot peel extracts with a high yield of bioactive compounds (citric acid concentration $-1.5 \%$, ethanol concentration- $50 \%$, temperature $-52.52{ }^{\circ} \mathrm{C}$, and extraction time $-49.9 \mathrm{~min})$. In the experiment, the interactions of time, temperature, and acid and solvent concentrations led to the improvement of compounds extraction in terms of the highest concentration of betalains ( $1.20 \mathrm{mg} / \mathrm{g} \mathrm{DW})$ and phenolic compounds (2.39 mg GAE/g DW). This study's novelty is optimizing the extraction protocol using conventional methods to improve the extraction of bioactive compounds from beetroot peels. Therefore, the method developed can be successfully utilized as a promising method for the efficient extraction of betalains and polyphenols from the beetroot peel for its economic utilization. Due to the significant concentration of valuable bioactive constituents from beetroot peel, multipurpose applications of these compounds could be found in different food industries and the pharmaceutical and nutraceutical industries.

Author Contributions: Conceptualization, G.R. and N.S.; methodology, G.R. and O.E.C.; validation, O.E.C., and S.L.; formal analysis, S.L.; investigation, S.L.; resources, N.S. and C.C.; data curation, I.A.; writing-original draft preparation, O.E.C. and G.R.; writing-review and editing, G.R. and I.A.; visualization, N.S.; supervision, C.C. All authors have read and agreed to the published version of the manuscript.

Funding: Doctoral Schools of Dunarea de Jos University of Galati (SCDS-UDJG) http:/ / www.cssdudjg.ugal.ro/ (accessed on 11 April 2021).

Institutional Review Board Statement: Not applicable.

Informed Consent Statement: Not applicable.

Data Availability Statement: The data that support the findings of this study are available from the corresponding author (G.R.) upon reasonable request.

Acknowledgments: The results of this work have been presented to the 9th edition of the Scientific Conference organized by the Doctoral Schools of "Dunărea de Jos" University of Galati (SCDS-UDJG) http:/ / www.cssd-udjg.ugal.ro/ (accessed on 11 April 2021) that will be held on 10th and 11th of June 2021, in Galati, Romania.

Conflicts of Interest: The authors declare no conflict of interest. 


\section{References}

1. Chawla, H.; Parle, M.; Sharma, K.; Yadav, M. Beetroot: A Health Promoting Functional Food. Inventi Rapid Nutraceuticals 2015, 2016, 0976-3872.

2. Wruss, J.; Waldenberger, G.; Huemer, S.; Uygun, P.; Lanzerstorfer, P.; Muller, U.; Hoglinger, O.; Weghuber, J. Compositional characteristics of commercial beetroot products and beetroot juice prepared from seven beetroot varieties grown in Upper Austria. J. Food Compos. Anal. 2015, 42, 46-55. [CrossRef]

3. Neha, P.; Jain, S.K.; Jain, N.K.; Jain, H.K.; Mittal, H.K. Chemical and Functional Properties of Beetroot (Beta vulgaris L.) for Product Development: A Review. Int. J. Chem. Stud. 2018, 6, 3190-3194.

4. Wootton-Beard, P.C.; Ryan, L. A Beetroot Juice Shot Is a Significant and Convenient Source of Bioaccessible Antioxidants. J. Funct. Foods 2011, 3, 329-334. [CrossRef]

5. Vorobiev, E.; Chemat, F. Principles of Physically Assisted Extractions and Applications in the Food, Beverage and Nutraceutical Industries. In Separation, Extraction and Concentration Processes in the Food, Beverage and Nutraceutical Industries; Syed, S.H., Rizvi, A., Eds.; Woodhead Publishing: Sawston, UK, 2013; pp. 71-108.

6. Liu, X.; Gao, Y.; Xu, H.; Wang, Q.; Yang, B. Impact of High-Pressure Carbon Dioxide Combined with Thermal Treatment on Degradation of Red Beet (Beta vulgaris L.) Pigments. J. Agric. Food Chem. 2008, 56, 6480-6487. [CrossRef] [PubMed]

7. Albano, C.; Negro, C.; Tommasi, N.; Gerardi, C.; Mita, G.; Miceli, A.; De Bellis, L.; Blando, F. Betalains, Phenols and Antioxidant Capacity in Cactus Pear [Opuntia ficus-indica (L.) Mill.] Fruits from Apulia (South Italy) Genotypes. Antioxidants 2015, 4, 269-280. [CrossRef]

8. Ravichandran, K.; Saw, N.M.M.T.; Mohdaly, A.A.A.; Gabr, A.M.M.; Kastell, A.; Riedel, H.; Cai, Z.; Knorr, D.; Smetanska, I. Impact of Processing of Red Beet on Betalain Content and Antioxidant Activity. Food Res. Int. 2013, 50, 670-675. [CrossRef]

9. Kumar, N.; Pruthi, V. Potential Applications of Ferulic Acid from Natural Sources. Biotechnol. Rep. 2014, 4, 86-93. [CrossRef]

10. Hobbs, D.A.; George, T.W.; Lovegrove, J.A. The Effects of Dietary Nitrate on Blood Pressure and Endothelial Function: A Review of Human Intervention Studies. Nutr. Res. Rev. 2013, 26, 210-222. [CrossRef]

11. Vidal, P.J.; López-Nicolás, J.M.; Gandía-Herrero, F.; García-Carmona, F. Inactivation of Lipoxygenase and Cyclooxygenase by Natural Betalains and Semi-Synthetic Analogues. Food Chem. 2014, 154, 246-254. [CrossRef] [PubMed]

12. Faridah, A.; Holinesti, R.; Syukri, D. Betalains from Red Pitaya Peel (Hylocereus polyrhizus): Extraction, Spectrophotometric and HPLC-DAD Identification, Bioactivity and Toxicity Screening. Pak. J. Nutr. 2015, 14, 976-982. [CrossRef]

13. Kusznierewicz, B.; Mróz, M.; Koss-Mikołajczyk, I.; Namieśnik, J. Comparative Evaluation of Different Methods for Determining Phytochemicals and Antioxidant Activity in Products Containing Betalains-Verification of Beetroot Samples. Food Chem. 2021, 362, 130132. [CrossRef]

14. Azmir, J.; Zaidul, I.S.M.; Rahman, M.M.; Sharif, K.M.; Mohamed, A.; Sahena, F.; Jahurul, M.H.A.; Ghafoor, K.; Norulaini, N.A.N.; Omar, A.K.M. Techniques for Extraction of Bioactive Compounds from Plant Materials: A Review. J. Food Eng. 2013, 117, 426-436. [CrossRef]

15. Ramli, N.S.; Ismail, P.; Rahmat, A. Influence of Conventional and Ultrasonic-Assisted Extraction on Phenolic Contents, Betacyanin Contents, and Antioxidant Capacity of Red Dragon Fruit (Hylocereus polyrhizus). Sci. World J. 2014, 2014, 964731. [CrossRef] [PubMed]

16. Hilou, A.; Millogo-Rasolodimby, J.; Nacoulma, O.G. Betacyanins are the most relevant antioxidant molecules of Amaranthus spinosus and Boerhavia erecta. J. Med. Plants Res. 2013, 7, 645-652.

17. Fu, Y.; Shi, J.; Xie, S.-Y.; Zhang, T.-Y.; Soladoye, O.P.; Aluko, R.E. Red Beetroot Betalains: Perspectives on Extraction, Processing, and Potential Health Benefits. J. Agric. Food Chem. 2020, 68, 11595-11611. [CrossRef] [PubMed]

18. Castro-Enríquez, D.D.; Montaño-Leyva, B.; Del Toro-Sánchez, C.L.; Juaréz-Onofre, J.E.; Carvajal-Millan, E.; Burruel-Ibarra, S.E.; Tapia-Hernández, J.A.; Barreras-Urbina, C.G.; Rodríguez-Félix, F. Stabilization of Betalains by Encapsulation-A Review. J. Food Sci. Technol. 2020, 57, 1587-1600. [CrossRef]

19. Zin, M.M.; Borda, F.; Márki, E.; Bánvölgyi, S. Betalains, Total Polyphenols, and Antioxidant Contents in Red Beetroot Peel (Cylindra Type). Prog. Agric. Eng. Sci. 2021, 16, 27-36.

20. Chhikara, N.; Kushwaha, K.; Sharma, P.; Gat, Y.; Panghal, A. Bioactive Compounds of Beetroot and Utilization in Food Processing Industry: A Critical Review. Food Chem. 2019, 272, 192-200. [CrossRef]

21. Das, M.; Saeid, A.; Hossain, M.F.; Jiang, G.-H.; Eun, J.B.; Ahmed, M. Influence of Extraction Parameters and Stability of Betacyanins Extracted from Red Amaranth during Storage. J. Food Sci. Technol. 2019, 56, 643-653. [CrossRef]

22. Tang, C.S.; Norziah, M.N. Stability of Betacyanin Pigments from Red Purple Pitaya Fruit (Hylocereus polyrhizus): Influence of pH, Temperature, Metal Ions and Ascorbic Acid. Indones. J. Chem. 2007, 7, 327-331. [CrossRef]

23. Sanchez-Gonzalez, N.; Jaime-Fonseca, M.R.; San Martin-Martinez, E.; Zepeda, L.G. Extraction, Stability, and Separation of Betalains from Opuntia Joconostle Cv. Using Response Surface Methodology. J. Agric. Food Chem. 2013, 61, 11995-12004. [CrossRef] [PubMed]

24. Latorre, M.E.; Narvaiz, P.; Rojas, A.M.; Gerschenson, L.N. Effects of Gamma Irradiation on Bio-Chemical and Physico-Chemical Parameters of Fresh-Cut Red Beet (Beta vulgaris L. var. conditiva) Root. J. Food Eng. 2010, 98, 178-191. [CrossRef]

25. Thirugnanasambandham, K.; Sivakumar, V. Influence of Process Conditions on the Physicochemical Properties of Pomegranate Juice in Spray Drying Process: Modelling and Optimization. J. Saudi Soc. Agric. Sci. 2017, 16, 358-366. [CrossRef] 
26. Krsnik-Rasol, M.; Pavoković, D. Complex Biochemistry and Biotechnological Production of Betalains. Food Technol. Biotechnol. 2011, 49, 145-155.

27. Lee, E.J.; An, D.; Nguyen, C.T.T.; Patil, B.S.; Kim, J.; Yoo, K.S. Betalain and Betaine Composition of Greenhouse- or Field-Produced Beetroot (Beta vulgaris L.) and Inhibition of HepG2 Cell Proliferation. J. Agric. Food Chem. 2014, 62, 1324-1331. [CrossRef]

28. Slatnar, A.; Stampar, F.; Veberic, R.; Jakopic, J. HPLC-MSnIdentification of Betalain Profile of Different Beetroot (Beta vulgaris L. Ssp. vulgaris) Parts and Cultivars. J. Food Sci. 2015, 80, C1952-C1958. [CrossRef]

29. Ninfali, P.; Angelino, D. Nutritional and Functional Potential of Beta vulgaris cicla and rubra. Fitoterapia 2013, 89, 188-199. [CrossRef]

30. Kavalcová, P.; Bystrická, J.; Tomáš, J.; Karovičová, J.; Kovarovič, J.; Lenková, M. The Content of Total Polyphenols and Antioxidant Activity in Red Beetroot. Potravin. Slovak J. Food Sci. 2015, 9, 77-83. [CrossRef]

31. Kovarovič, J.; Bystrická, J.; Tomáš, J.; Lenková, M. The Influence of Variety on the Content of Bioactive Compounds in Beetroot (Beta vulgaris L.). Potravin. Slovak J. Food Sci. 2017, 11, 106-112. [CrossRef]

32. Yasaminshirazi, K.; Hartung, J.; Fleck, M.; Graeff-Hoenninger, S. Bioactive Compounds and Total Sugar Contents of Different Open-Pollinated Beetroot Genotypes Grown Organically. Molecules 2020, 25, 4884. [CrossRef] [PubMed] 